\title{
Communication of IPCC visuals: IPCC authors' views and assessments of visual complexity
}

Check for updates

\section{Jordan Harold ${ }^{1}$ (D) $\cdot$ Irene Lorenzoni ${ }^{2}$ (ID $\cdot$ Thomas F. Shipley $^{3}$ (D) $\cdot$ Kenny R. Coventry ${ }^{4}$ (I)}

Received: 27 February 2019 / Accepted: 19 August 2019 / Published online: 4 December 2019

(C) The Author(s) 2019

\begin{abstract}
Scientific figures, i.e. visuals such as graphs and diagrams, are an important component of Intergovernmental Panel on Climate Change (IPCC) reports that support communication and policy-making. It is therefore imperative that figures are robust representations of the science and are accessible to target audiences. We interviewed IPCC authors $(n=18)$ to understand the development of figures in the IPCC Fifth Assessment Report (AR5) Working Group 1 (WG1) Summary for Policy-Makers (SPM). Authors expressed the view that the need to maintain scientific accuracy constrained making figures more accessible, with the consequence that figures retained complexity and often required specialists to explain the figures to others. Using sort tasks with IPCC authors and with a group of non-specialists (undergraduate students; $n=38$ ), we found that IPCC authors generally had good awareness of which figures non-specialists perceived as being most difficult to understand. Further, by evaluating the visual complexity of the AR5 WG1 SPM figures using a computational measure, we found that greater visual complexity (i.e. high quantity of information, use of multiple colours and densely packed visual elements) is associated with greater perceived comprehension difficulty. Developing and integrating computational approaches to assess figures alongside user testing could help inform how to overcome visual complexity while maintaining scientific rigour and so enhance communication of IPCC figures and scientific visuals.
\end{abstract}

Electronic supplementary material The online version of this article (https://doi.org/10.1007/s10584-019$02537-z)$ contains supplementary material, which is available to authorized users.

Jordan Harold

Jordan.Harold@uea.ac.uk

1 School of Psychology and Tyndall Centre for Climate Change Research, University of East Anglia, Norwich Research Park, Norwich NR4 7TJ, UK

2 School of Environmental Sciences, Tyndall Centre for Climate Change Research, and Science, Society and Sustainability (3S) Research Group, University of East Anglia, Norwich Research Park, Norwich NR4 7TJ, UK

3 Department of Psychology, Temple University, Philadelphia, PA 19122, USA

4 School of Psychology, University of East Anglia, Norwich Research Park, Norwich NR4 7TJ, UK 
Keywords IPCC $\cdot$ Climate science $\cdot$ Complexity $\cdot$ Science communication $\cdot$ visual design

\section{Introduction}

The IPCC AR5 has been widely acknowledged as being instrumental in motivating the Paris Agreement, which aims to keep global temperature rise this century well below $2{ }^{\circ} \mathrm{C}$ and to pursue efforts to limit warming to $1.5^{\circ} \mathrm{C}$ (Lynn 2018). However, despite the success of AR5, its reports have been criticised for being difficult to understand and inaccessible to nonspecialist audiences, including policy-makers (IPCC 2016a). Criticism has primarily focussed on poor readability of the text of Summary for Policy-Makers (SPMs) (Barkemeyer et al. 2016; Budescu et al. 2014; but see Mach et al. 2016). And while AR5 authors sought ways to make the text of reports more accessible with the use of headline statements (Stocker and Plattner 2016), it is not known to what extent efforts were taken to make the figures accessible. Indeed, despite the prominence of figures in SPMs and IPCC outreach activities, prior research has largely neglected to consider the accessibility and comprehension of the AR5 SPM figures, nor sought to capture the perspectives of authors involved in producing the figures (but for discussion, see IPCC 2016a and Harold et al. 2016). Doing so could help enhance the accessibility of climate change information for the IPCC Sixth Assessment reports.

Poor comprehension of a figure can result in misinterpretation. For example, non-specialists often misattribute representations of scenario uncertainty to model uncertainty (McMahon et al. 2015), and the use of inverted axes and logarithmic scales can lead readers to make erroneous inferences (Fischer et al. 2018). Critically, different audiences use contrasting mental strategies to interpret scientific figures (Stofer and Che 2014), and the format and style of a figure can influence the nature of inferences made about future climate (Daron et al. 2015; Bosetti et al. 2017). Consequently, successful comprehension of a figure is dependent on design choices (within the control of authors) and characteristics of the audience (outside the control of authors) (Hegarty 2011).

The IPCC broadly identifies their primary audience as 'governments and policy-makers at all levels' (IPCC 2012, p.3), but policy-makers are a heterogeneous group of individuals and SPMs do not explicitly identify a particular type of policy-maker as their intended audience. While there is broad interest in IPCC outputs, including among climate change specialists, government ministers, and the public (IPCC 2016a), it is not known to what extent authors consider the diversity of audiences when developing SPM figures, nor what factors in the process of writing reports constrain the design and communication of the figures. For example, it might be that authors try to develop SPM figures suitable for a broad policy audience, but are unaware of the types of figures that might be comparatively more difficult to comprehend. Conversely, authors might develop SPM figures targeted to particular specialists within government and have good awareness of the nature of comprehension difficulties among broader audiences.

Here, we report findings from in-depth interviews with 18 IPCC WG1 authors to understand the requirements of SPM figures, the process for their design, the intended target audiences and perceived communication challenges for the figures in the IPCC AR5 WG1 SPM (IPCC 2013a). Although criticism of IPCC communications has not been confined to a specific Working Group, our analysis here focuses on WG1 as it was the most recently published IPCC report when the present research was initiated. Through a series of sort tasks using the AR5 WG1 SPM figures, we also compare authors' and non-specialists' (university undergraduates) perceptions of which figures are comparatively easier or more difficult to 
comprehend, and authors' views on which figures are most important to inform future climate policy. Finding that authors typically attribute difficulties in comprehending certain figures with multiple facets of visual complexity, we then consider the association between the visual complexity of SPM figures and non-specialists' perceptions of comparative ease/difficulty, using an objective computational metric of visual complexity (subband entropy).

This mixed methodological approach serves two purposes. First, we aim to provide the science community with a deeper understanding, from the perspective of IPCC authors, of the primary audience that SPM reports and figures (aim to) reach, together with an understating of the constraints that authors faced in the process of their creation. Such insights may be useful to inform and contextualise future critiques of IPCC SPM figures. Second, we aim to identify visual characteristics of SPM figures that contribute to visual complexity and comparative comprehension difficulty, and demonstrate the value of evaluating the degree of visual complexity within visuals to inform the communications design of technical climate science visuals. We hope these insights will be informative for IPCC author teams working on future SPMs, and for the broader climate change community when developing robust and accessible climate science data visuals.

\section{Interviews with IPCC authors}

\subsection{Interview participants}

Eighteen interviews were conducted - 17 with individuals listed either as drafting authors or draft contributing authors to the IPCC AR5 WG1 SPM (IPCC 2013a) and one interview was conducted with an author who had worked previously with the IPCC. There was an $82 \%$ participation rate (22 authors contacted to take part, 18 agreed, representing $24 \%$ of all SPM authors). Stratified sampling was employed to ensure that, where possible, variation in geographic representation, gender, role in authorship and area of expertise (across the report's underlying chapters) was reflective of the full set of authors to the AR5 WG1 SPM. Post hoc power analysis (Fugard and Potts 2015) revealed 87\% power to detect at least nine participants articulating any given sub-theme where that sub-theme has at least $60 \%$ prevalence among the complete set of IPCC WG1 AR5 SPM authors.

\subsection{Interview protocol}

Interviews were conducted between March 2014 and February 2015, face-to-face or via video conference and in both cases, lasted approximately $1 \mathrm{~h}$. For participants taking part remotely via video conference, an interview pack was mailed to them beforehand. Participants gave informed consent prior to the start of the interview. All interviews were audio recorded (with participants' consent) to enable verbatim transcription. The semi-structured interview protocol covered the following topics:

- the audiences of the figures

- the purpose of the figures

- the process through which the figures are created

- strengths and weaknesses of the figures

- the use of the figures by the IPCC and by others 
Ten A5 cards containing the ten AR5 Working Group 1 SPM figures, without their associated captions, were provided to participants at certain stages of the interview to aid their thinking. The interview protocol was followed to guide the overall structure of the interview. Additional follow-up questions and clarification questions were asked by the interviewer to explore answers in more depth. At the end of the interview, participants were offered the opportunity to add any additional comments or clarifications and were then debriefed.

\subsection{Interview data analysis}

Thematic analysis was used to extract themes from the interviews. Thematic analysis is a flexible tool to code qualitative data using a rigorous and systematic approach, while acknowledging the 'active' role that the researcher takes in conducting the analysis - i.e. prescribing meaning in a given context (Braun and Clarke 2006). A 'critical realist' approach was adopted (Clarke et al. 2015), in which the data analysis reports the production and communication of the SPM figures from the perspective of the authors, but acknowledges that these experiences are formed within the broader context of the use of science and its communication in society. Further, the analytical approach was inductive; themes were identified by keeping as closely as possible to the semantic meanings within the data. Descriptive reporting was accordingly adopted to summarise and describe the identified themes (Clarke et al. 2015).

The thematic analysis was conducted as per the six phases outlined by Braun and Clarke (2006). Interviews were transcribed verbatim, covering the full length of the interview, except for initial introductions. Initial codes were generated to identify interesting aspects in the data. Codes were then mapped to identify similarities and links between codes and to search for potential themes. Candidate themes were then reviewed, referring back to the data, at which point some themes were dropped if they lacked adequate support across interviews. Themes and sub-themes were then refined, defined and named (Table 1). Inter-rater reliability for coded sub-themes on a sample of $15 \%$ of the data was $\kappa=0.802$ (95\% CI, 0.685 to 0.919 ), $p<0.001$.

\subsection{Interview findings}

\subsubsection{Authors' views on the communication of IPCC report figures}

We identified three central themes (each with supporting sub-themes) that help explain the approach to communication for the AR5 WG1 SPM figures: (1) the need to maintain scientific rigour, (2) the provision of communication for specialists (rather than non-specialist policymakers) and (3) an awareness of communication issues, in part overcome by providing explanations to support comprehension (Table 1). We next elaborate on these central themes.

\subsubsection{A need to maintain scientific rigour}

Due to the IPCC's remit to produce scientifically robust reports, authors perceived a limit to which information in SPM figures could be simplified without losing accuracy, and complexity was retained to maintain rigour; 'There is a desire to have the technical content be pretty accurate, and maybe in some sense complete, and so the figure (referring to SPM figures in general) can get a little bit complicated....' Achieving rigour focussed on figures being '... traceable to the underlying chapters', and content being reviewed through '... a lot of scientific questioning and rigorous checks'. Authors described collaborative efforts to refine and iterate 
Table 1 Themes and sub-themes that explain the communication design of IPCC AR5 WG1 SPM figures, from the perspective of IPCC authors. Number of interviews in which sub-themes were identified is shown in parentheses

\begin{tabular}{|c|c|c|}
\hline Theme & Sub-theme & Description \\
\hline \multirow[t]{3}{*}{$\begin{array}{l}\text { A need to maintain } \\
\text { scientific rigour }\end{array}$} & $\begin{array}{l}\text { Use of report chapters as source } \\
\quad(18 / 18)\end{array}$ & $\begin{array}{l}\text { Information presented in figures has 'line of sight' } \\
\text { back to underlying report chapters }\end{array}$ \\
\hline & $\begin{array}{l}\text { Specialists review and amend } \\
(14 / 18)\end{array}$ & $\begin{array}{l}\text { Specialists (including those within government) } \\
\text { review figures, and authors edit figures }\end{array}$ \\
\hline & $\begin{array}{l}\text { Retention of informational } \\
\text { complexity }(14 / 18)\end{array}$ & $\begin{array}{l}\text { Scientific details are kept in figures to ensure } \\
\text { completeness and accuracy }\end{array}$ \\
\hline \multirow{4}{*}{$\begin{array}{l}\text { A focus on } \\
\text { communicating } \\
\text { with specialists }\end{array}$} & $\begin{array}{l}\text { To provide policy relevant } \\
\text { information }(16 / 18)\end{array}$ & $\begin{array}{l}\text { Figures aim to communicate policy relevant } \\
\text { information, often to inform decision-making }\end{array}$ \\
\hline & To tell a story $(13 / 18)$ & $\begin{array}{l}\text { Figures are used to highlight key messages, which } \\
\text { together form a narrative }\end{array}$ \\
\hline & $\begin{array}{l}\text { Targeting technical analysts } \\
(18 / 18)\end{array}$ & $\begin{array}{l}\text { Figures are aimed at specialists working within } \\
\text { government (and not for a broader range of policy } \\
\text { makers) }\end{array}$ \\
\hline & $\begin{array}{l}\text { Targeting the scientific } \\
\text { community }(14 / 18)\end{array}$ & $\begin{array}{l}\text { Figures are useful resources for scientists (e.g. to } \\
\text { support research and teaching) }\end{array}$ \\
\hline \multirow{3}{*}{$\begin{array}{l}\text { An awareness of } \\
\text { communication } \\
\text { issues }\end{array}$} & $\begin{array}{l}\text { High degree of visual } \\
\text { complexity }(15 / 18)\end{array}$ & $\begin{array}{l}\text { Retaining informational complexity often results in } \\
\text { figures that are visually complex }\end{array}$ \\
\hline & $\begin{array}{l}\text { Awareness of easy and difficult } \\
\text { to understand visual formats } \\
(9 / 18)\end{array}$ & $\begin{array}{l}\text { Awareness that unfamiliar visual formats and features } \\
\text { may be more difficult to understand than familiar } \\
\text { formats (e.g. maps, simple bar graphs) }\end{array}$ \\
\hline & $\begin{array}{l}\text { A need to provide explanations } \\
\text { to guide comprehension } \\
(17 / 18)\end{array}$ & $\begin{array}{l}\text { Supplementary text and verbal explanations are } \\
\text { considered important to support comprehension of } \\
\text { figures }\end{array}$ \\
\hline
\end{tabular}

figures in response to review comments, including efforts to improve the communications design, but did not draw on support from communications specialists; '... there is no expert on perception or visual communication, or in fact any communication person directly involved.'

\subsubsection{A focus on communicating with specialists}

Authors described policy relevance as the main criterion for presenting information in a SPM figure, as is consistent with the aims of the IPCC (IPCC 2013b). They saw figures as a way to highlight '... the most important scientific messages to convey', which collectively were seen to '...make a story' by acting as '...pillars of the entire narrative'. Authors described the primary audience of the figures as knowledgeable expert 'analysts' or 'technical advisors', rather than policy makers per se; '...it says for policy makers, but actually I think it's for policy analysts within government departments.' The climate science community was also commonly identified as a secondary audience; '...it provides a kind of synthesis of the science for other scientists.'; 'They're useful for scientists' (referring to those researching or teaching climate issues). Hence, there is a disconnection between these specialist audiences and broader audiences of SPMs.

\subsubsection{An awareness of communication issues}

In the context of maintaining scientific rigour and communicating with specialist audiences, authors had an awareness that the figures can become complex, both in terms of the information conveyed and in their visual representation. Authors acknowledged that many figures are inaccessible to broader audiences; '. ... they're very hard to interpret by themselves I 
would say.' Although the density of information within SPM figures was seen in a positive light, in that it can '... save a lot of text' and convey '... a lot of complex information in a fairly concise and efficient manner', the resulting visual complexity was acknowledged to impair comprehension; '...it's just way too busy and you have to spend five minutes looking at it.' Specific aspects of visual complexity identified by authors included the use of numerous visual elements (to represent different types of information), use of multiple colours, use of visual elements in close proximity, i.e. with high density in response to limited page space, and the use of visual elements that lack clarity in meaning (Table 2). The type of figure influenced perceptions of ease of comprehension, for example, with simple line graphs generally considered to be the most easily understood, 'The time series people understand better in general.'

While some felt the text in the report and figure captions provided adequate guidance to interpret the figures, others emphasised the need for '... a lot of explanation'. Indeed, this view was expressed in relation to both specialist and non-specialist audiences '...even to explain to another scientist, this figure takes some work.'; '...without additional explanation they are probably not very useful communication tools.' Hence, although authors perceived visual complexity to be a barrier to comprehension, they typically felt this could be overcome if they explained the content, thus placing the authors as 'gatekeepers' to knowledge.

\section{Perceptions of figure ease of comprehension and importance}

To understand the types of figures that are perceived to be comparatively easier or more difficult to understand, we asked IPCC authors and non-specialists (university undergraduates not studying climate science) to rank the ten AR5 WG1 SPM figures for their ease of comprehension. Within the interviews, authors were asked to rank the ten SPM figures in terms of their ease of comprehension for undergraduate students, and separately, for their ease of comprehension for policy-makers. Undergraduate students were simply asked to look at the figures and order them from the easiest to the most difficult to understand. Thus, we ask whether authors' rankings for university undergraduates are similar to their rankings for policy-makers and whether authors are calibrated to the types of figures that non-specialists perceive as being comparatively more difficult to comprehend. Further, to understand associations between the comparative ease of comprehension and the relative importance of figures, we asked IPCC authors to rank the figures based on their importance for informing future climate policy. Figures deemed particularly important might be designed to be comparatively easy to understand. Alternatively, important figures might tend to contain complex information and may therefore tend to be difficult to understand.

\subsection{Sort tasks with IPCC authors}

The same authors who took part in the interviews completed three sort tasks using the ten figures from the IPCC AR5 WG1 SPM (without text captions) as stimuli. At the start of each interview, participants were asked to 'Rank order the figures from the one you think university undergraduates without climate science training would find easiest to understand through to the one that you think they would find the most difficult to understand.' Mid-way through the interview we asked participants to 'Rank order the figures from the one you think policymakers would find easiest to understand through to the one that you think they would find the most difficult to understand.' A final sort task at the end of the interview asked participants to 
Table 2 Aspects of complexity identified by IPCC WG1 authors, with examples from the AR5 WG1 SPM. Associated dimensions of perceptual visual complexity shows components of complexity from a psychological and computational perspective, further outlined in Online Resource 4. SPM figures can be accessed at https://www.ipcc.ch/report/ar5/wg1/summary-for-policymakers/

\begin{tabular}{ll}
\hline $\begin{array}{l}\text { Aspects of complexity } \\
\text { identified by authors }\end{array}$ & Examples from AR5 WG1 SPM figures
\end{tabular} \begin{tabular}{l}
$\begin{array}{l}\text { Associated dimension } \\
\text { of perceptual visual } \\
\text { complexity (see } \\
\text { Online Resource 4) }\end{array}$ \\
\hline
\end{tabular}

\begin{tabular}{|c|c|c|}
\hline $\begin{array}{l}\text { Multiple visual information } \\
\text { elements i.e. multiple panels, } \\
\text { multiple datasets, multiple } \\
\text { variables, multiple scenarios, } \\
\text { and representation of } \\
\text { uncertainty }\end{array}$ & $\begin{array}{l}\text { SPM3c-multiple lines for different datasets } \\
\text { SPM5-partitions within bars for resulting } \\
\text { atmospheric drivers; uncertainty intervals } \\
\text { SPM6-multiple panels for different regions } \\
\text { SPM10 - additional line and shaded area to show } \\
1 \% \text { year-1 } \mathrm{CO}_{2} \text { multi-model mean and range }\end{array}$ & Quantity \\
\hline $\begin{array}{l}\text { Multiple colours i.e. to denote } \\
\text { different types of information }\end{array}$ & $\begin{array}{l}\text { SPM3c-multiple colours for different datasets } \\
\text { SPM5 - multiple colours for different atmospheric } \\
\text { drivers } \\
\text { SPM6-multiple panel background colours for } \\
\text { different indicators }\end{array}$ & Variety \\
\hline $\begin{array}{l}\text { High density of visual elements i.e. } \\
\text { elements are 'packed in' } \\
\text { making them difficult to read } \\
\text { and/or interpret }\end{array}$ & $\begin{array}{l}\text { SPM5-bars, diamonds, error bars, confidence } \\
\text { indicators } \\
\text { SPM6-panels for regions and panels for global } \\
\text { averages, each showing observations (lines) and } \\
\text { model ranges (shaded areas) }\end{array}$ & Openness \\
\hline $\begin{array}{l}\text { Visual and/or text elements that } \\
\text { may lack clarity in intended } \\
\text { meaning e.g. symbols, } \\
\text { acronyms, jargon, numeric } \\
\text { labels that lack a referent class }\end{array}$ & $\begin{array}{l}\text { SPM 1-'+' symbol to denote a significant trend } \\
\text { SPM4-pH scale to denote level of } \\
\text { acidity/alkalinity } \\
\text { SPM5-acronyms (e.g. NMVOC) and molecular } \\
\text { formulae } \\
\text { SPM7—numeric labels above/below time series to } \\
\text { denote the number of models used to calculate } \\
\text { the multi-model mean } \\
\text { SPM8-hatching and stippling to contextualise } \\
\text { multi-model mean to natural internal variability } \\
\text { SPM7, SPM8, SPM9, SPM10-RCP acronym to } \\
\text { denote 'representative concentration pathway' }\end{array}$ & Not applicable \\
\hline
\end{tabular}

'Rank order the figures based on their importance to help inform future climate policy, from the one you think is the most important through to the one that you think is least important.'

At the start of each sort task, the ten cards were spread out in a random order in front of the participant and they were then asked to order the cards in a line in answer to the question presented. There was no time limit to the task, but participants typically took approximately 12 min to decide on an order.

\subsection{Sort task with undergraduate students}

Thirty-eight undergraduate students at the University of East Anglia took part and received course credit or a nominal payment for their participation. Twenty-seven students were female and 11 were male; mean age was 21 years (range 18-30 years). The majority of the undergraduate students were studying psychology — none were studying environmental sciences.

Undergraduate students took part individually in a quiet room following completion of a separate research study. Participants were seated at a desk and were provided with the following 
instructions to read, 'You will be given a set of 10 cards. Each card will show one or more graphs or diagrams. You will be asked to take a few minutes to look at the contents on the cards - as you do, try to work out what you think the graphs and diagrams are trying to show. Then, please sort the cards in order from the one that you find the easiest to understand (rank 1), through to the one that you find the hardest / most difficult to understand (rank 10).'

The ten cards showing the ten IPCC AR5 WG1 SPM figures (without text captions) were spread out in a random order and participants were asked to order the cards in a line with the easiest on their left and most difficult on their right. There was no time limit to the task, and participants typically took approximately 3-4 min to decide on an order.

\subsection{Sort task results}

For each sort-task, we first checked the extent to which individuals' rankings of the figures agreed. We found moderate to strong concordance among authors and among undergraduates in each of the sort-tasks (see Online Resource 1).

\subsubsection{Ease of comprehension}

We found a positive correlation between authors' rankings about undergraduates' ease of comprehension and authors' rankings about policy-makers' ease of comprehension, indicating that authors' rankings for each audience were similar. We also found a positive correlation between authors' rankings about undergraduates and the average rankings given by undergraduates (Table 3). Authors' rankings broadly matched undergraduates' rankings (Online Resource 2), and there was agreement between audiences that figures SPM4 and SPM5 (Online Resource 3) were the easiest and most difficult to comprehend, respectively (Table 4 and Online Resource 2). Hence, authors had awareness of which figures (from the set of ten) that non-specialists perceived to be comparatively more difficult to understand.

\subsubsection{Importance for future climate policy}

There was strong concordance among authors in their rankings of the figures for their relative importance to inform future climate policy (Online Resource 1), but we found no association between the ranked importance of the figures and ranked ease of comprehension (Table 3). Figure SPM10 (Online Resource 3), which shows the relationship between anthropogenic $\mathrm{CO}_{2}$ emissions and global mean surface temperature, was selected as the most important figure by 15 of the 18 interviewed authors. Intriguingly, non-specialists considered figure SPM10 to be comparatively easier to understand, relative to other figures, than authors expected (Table 4 and Online Resource 2). We suggest that this difference might reflect that non-specialists made intuitive judgements based on visual characteristics of this figure, rather than a deeper understanding of the content (cf. Evans and Stanovich 2013). This indicates the potential for miscommunication if readers superficially interpret figures and highlights the importance of empirically testing figures with audiences to understand how design choices interact with what people are actually able to infer. Compared with the convergence among authors on figure SPM10 being the most important figure of the set for future climate policy, there was more variation in rankings for the remaining figures. 


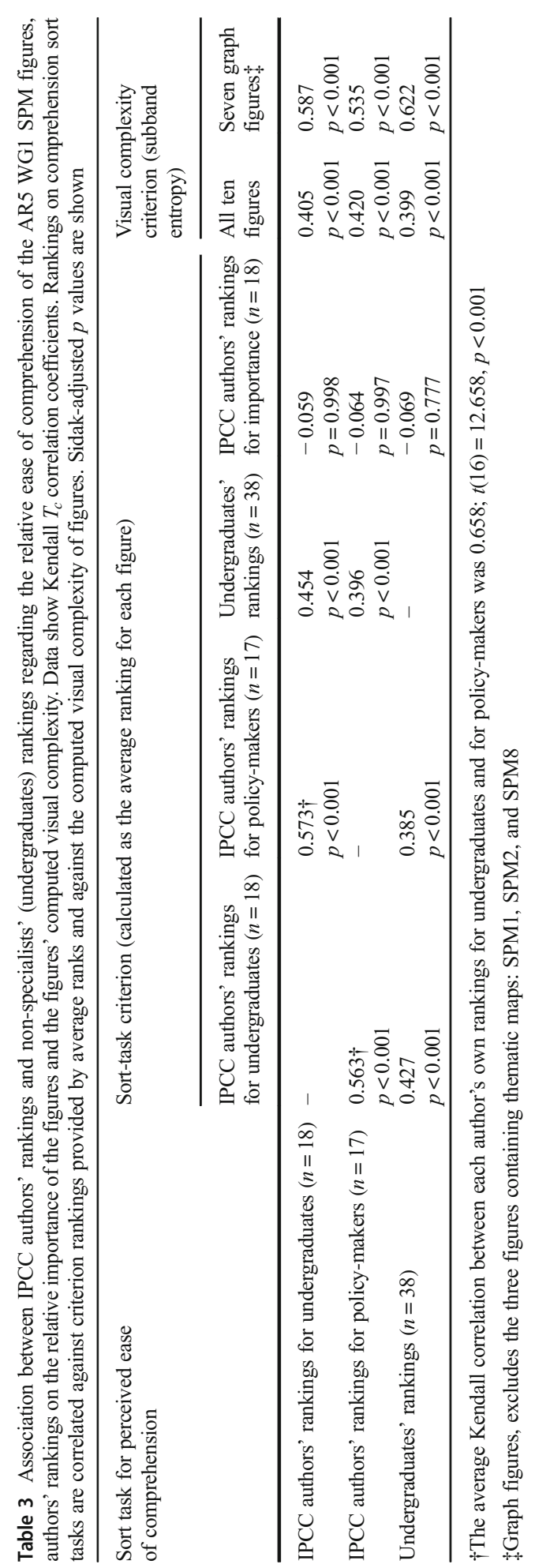









\section{Figure visual complexity}

The general agreement between IPCC authors and non-specialists in rankings across the set of ten figures, together with concordance within groups, suggests that a common criterion was used as basis for judgements. From a psychological and information processing perspective on visual perception, visual complexity is thought to be increased when there is high entropy-i.e. where high variability in visual features leads to lower predictability of visual information from one part of the visual to adjacent parts (Rosenholtz et al. 2007). Dimensions of visual complexity from a perceptual perspective include quantity, organisation, variety and openness of information (Olivia et al. 2004) (see Online Resource 4 for schematic examples). Images that are high in visual complexity are known to impair visual search (i.e. locating information) (Neider and Zelinsky 2011) and ease of interpretation (Baldassi et al. 2006). In interviews, IPCC authors identified aspects of complexity that map to dimensions of perceptual visual complexity (Table 2), and these aspects tended to be contained in figures that non-specialists ranked as being comparatively more difficult to comprehend.

To investigate the association between visual complexity and ranked ease of comprehension, we computed the subband entropy of each figure. Subband entropy evaluates the digital encoding efficiency of an image by breaking it down into subbands of different orientations and spatial frequencies, broadly analogous with human early visual processing, which can predict human performance on visual search tasks (Rosenholtz et al. 2007).

\subsection{Visual complexity/clutter measure}

The ten IPCC AR5 WG1 SPM figures were cropped to the edge of the images (so that complexity/clutter was measured on the visual content). Images were exported as jpeg files, with maximum pixel dimensions of 740 pixels high by 540 pixels wide. An index of visual complexity for each figure was calculated using the subband entropy clutter measure (Table 4). Subband entropy was chosen over the alternative measures of feature congestion and edge density, because subband entropy explicitly evaluates the degree of spatial organisation in a visual (Rosenholtz et al. 2007), and the spatial organisation of information and the visualspatial patterns that emerge are known to support cognition (Hegarty 2011).

\subsection{Visual complexity results}

We found that the greater the visual complexity of figures, the greater the ranked comprehension difficulty when judged by non-specialists and when judged by authors taking the perspective of non-specialists and policy-makers (Table 3). Subband entropy was comparable to authors' judgements in predicting non-specialists' rankings of figures for ease of comprehension. As the visual elements of thematic maps (such as outlines of continents) may confer a degree of visual complexity when measured by subband entropy, but which may not be perceived by people to be complex due to their iconic nature (Hegarty 2011), we performed sub-analyses excluding three figures that contained thematic maps (figures SPM1, SPM2, and SPM8). Among the remaining graph figures, we found strong positive correlations between visual complexity and rankings of comprehension difficulty (Table 3). Hence, evaluating the visual complexity of scientific figures during the drafting process could help to quickly identify figures that may be particularly difficult for audiences to understand and so help inform design choices. 


\section{Discussion}

\subsection{Overcoming challenges to visual communications}

Our findings demonstrate that when looking at IPCC SPM figures, non-specialists associate greater visual complexity with comparatively greater perceived comprehension difficulty. While IPCC authors had an awareness of the potential complexity of SPM figures, maintaining scientific rigour, making efficient use of page space and catering to the needs of specialist audiences were identified as constraints in making the figures more accessible. Although SPM figures support the narrative of the reports, their visual complexity is a constraint to effective communication. And while this may be lessened if experts provide explanations (for example, as happens at IPCC approval sessions with governments and at outreach events), this is not a feasible solution to ensure comprehension among a wider readership, given that IPCC authors volunteer their time, are already over-stretched (Stocker and Plattner 2014) and are unable to interact directly with all audiences (IPCC 2016a).

Our interviews with IPCC authors also revealed that they typically considered specialist/ technical analysts within government as the primary audience for the AR5 WG1 SPM, rather than broader government/policy audiences indicated by the IPCC (IPCC 2012), or nonspecialist audiences suggested by others (Barkemeyer et al. 2016; Black 2015; McMahon et al. 2015). Although specialists within the government may provide a channel through which reports are communicated with broader policy-makers, this finding, together with the constraints identified above, indicate that choices in the communication design of the SPM figures were primarily made in the context of a specialist, rather than a non-specialist, audience.

The key to any successful communication is tailoring information to the target audience. Hence, clarity of who the (broader) audiences are and knowledge of their information needs and level of prior knowledge would help enable authors to design SPM figures with this in mind. There is also an opportunity for greater co-production with target audiences (Rapley et al. 2014) - a process that already happens to some extent between authors and government specialists through IPCC review and approval processes, but which could be strengthened by integrating user testing and co-production of figures with broader audiences.

Efforts to improve the communication of IPCC SPM figures need to be mindful of the constraints faced by authors, associated constraints of IPCC processes (Lynn 2018), and the need to avoid over-simplification to maintain scientific credibility (McMahon et al. 2016). Given that in our interviews, IPCC authors identified aspects of complexity that map to dimensions of perceptual visual complexity (Olivia et al. 2004) and that increasing visual complexity (measured objectively using subband entropy) was associated with increased perceived comprehension difficulty, approaches to reduce visual complexity, rather than informational complexity, could help improve the accessibility of future SPM figures without compromising scientific rigour.

Alternative visual representations of the same information are not necessarily computationally (cognitively speaking) equivalent (Larkin and Simon 1987). Design solutions could therefore aim to avoid the inclusion of unnecessary visual elements; for example, by considering whether information needed for rigour but not integral for interpretation could be provided in text, or in a supporting table or figure. In addition, figures could be designed to avoid densely packed visual elements with greater page space devoted to 'unpacking' and building up information in manageable units. Figures could avoid unnecessary variety of colour, with only a sparing use of colour to help convey meaning and support interpretation. In 
addition, comprehension could be guided through figure titles and text annotations (see Harold et al. 2016 for an example). Developing SPM figures informed by such cognitive principles could make information more accessible to both specialist and non-specialist audiences.

Our findings indicate an association between authors' and non-specialists' rankings of figures for ease of comprehension. However, the ranking data does not indicate the absolute extent to which the figures are, or are not, actually comprehended. Previous research has demonstrated low levels of comprehension for IPCC figures among non-specialist audiences (Fischer et al. 2018; McMahon et al. 2015) suggesting that the figures ranked by nonspecialists as being difficult to understand may indeed be poorly understood. Furthermore, divergence in rankings for comprehension between authors (about non-specialists) and nonspecialists can highlight figures at risk of being less understood than might be expected. For example, not only was figure SPM10 deemed the most important figure for future climate policy but also authors tended to rank it as being more difficult for non-specialists to comprehend than non-specialists did (relative to other figures). In the interviews, some authors recounted experiences presenting figure SPM10 in which they felt they had to carefully explain what the shaded area and data lines show to enable people to understand it. Hence, it might be that when non-specialists initially inspect this figure, they are over-confident in interpreting it and do not realise what they do not understand (cf. Fischer et al. 2018). However, independent of their absolute comprehension difficulty, both authors and nonspecialists believed that figures SPM5 and SPM6 were among the most difficult to comprehend. Both of these figures also had comparatively high visual complexity (subband entropy) scores. Ranking data and visual complexity metrics can therefore provide useful indicators of figures that could benefit from further follow-up as part of efforts to improve accessibility of figures.

Although our sample of undergraduate students is not representative of the primary audience for SPM figures that authors identified in interviews (i.e. technical experts working in government), evidence suggests that students may be a reasonable proxy for the wider policy audiences that the IPCC wishes to reach. Comprehension of figures from an underlying chapter of AR5 have been found to be similar among university students and delegates to the United Nations Framework Convention on Climate Change (UNFCCC) Conference of the Parties (COP) (Fischer et al. 2018). However, such wider audiences are diverse, ranging across non-governmental organisations, the education sector, business and the public (IPCC 2016b), and differences in prior knowledge between these groups may influence their ability to comprehend IPCC SPM figures. Therefore, identifying sources of comprehension difficulty that create challenges for understanding across different audiences can provide pragmatic and actionable insights. Given commonalities in perceptual dimensions of complexity across individuals (Olivia et al. 2004), efforts to reduce visual complexity within figures could help enhance their accessibility across audiences.

\subsection{Looking ahead}

Reconciling the different needs of specialist and non-specialist audiences in SPMs is a challenging proposition, but one which the IPCC is striving to meet (IPCC 2016c). For the Special Report on Global Warming of $1.5^{\circ} \mathrm{C}$ (IPCC 2018a), guidance was provided to authors to support communication (Corner et al. 2018) and expertise from cognitive scientists and communications designers was embedded into the process of drafting SPM figures (IPCC 2018 b). With two further special reports to be published in 2019 , followed by the Sixth 
Assessment Report in 2021-2022, there is an opportunity to build on these initiatives by evaluating visual complexity, undertaking user testing and extending co-production between scientists, (specialist) policy-makers, non-specialist audiences and communications experts to help realise accessible and scientifically robust visual communications on climate change. Such efforts could help address criticism of SPMs being 'summaries for wonks' (Black 2015, p. 283) and enable them to move towards 'summaries for policymakers and society'.

Furthermore, in light of the policy relevance of IPCC SPMs, there is also a need to understand how the design of figures can better support policy processes and decision-making. The format of a figure can affect the extent to which policy-makers integrate climate data with their prior beliefs (Bosetti et al. 2017) and more broadly, the level of prior knowledge one has of a figure's format and content can affect how the figure is cognitively processed when making decisions (for a review, see Padilla et al. 2018). Consequently, future research on the communication of IPCC figures should consider their ease of comprehension alongside the extent to which they support readers in making useful inferences (e.g. to support policymaking).

The challenges faced by the IPCC are not unique. With growing demand for climate services, the need to make robust climate information accessible and user-friendly is becoming more acute (Hewitson et al. 2017; Brasseur and Gallardo 2016). Developing computational approaches that can quickly capture audience perspectives opens the door to developing algorithm-based metrics as proxies for human understanding to complement traditional user testing of visual communications. Such metrics could provide timely and meaningful evaluations of draft figures, and so inform and ultimately improve the design of climate science communications.

Acknowledgements We thank Corinne Le Quéré for providing introductions with interviewees.

Author contributions All authors contributed to the study conception, study design and interpretation of the data. Data collection and data analysis was conducted by J.H. The manuscript was drafted and prepared by J.H. with critical feedback and edits from I.L., T.F.S. and K.R.C.

Funding information This work was supported by a $\mathrm{PhD}$ Studentship from the School of Psychology, University of East Anglia (UEA) to J.H. and support from the Spatial Intelligence and Learning Centre (SILC), Temple University (SBE-1041707 from the National Science Foundation) including a travel grant to J.H.

Data availability Interview transcripts are not made available as participants could be identifiable from them. Data for the sort tasks and visual complexity scores are available at https://doi.org/10.17605/OSF.IO/6QD3N

\section{Compliance with ethical standards}

Competing interests Subsequent to this research, J.H., I.L. and K.R.C. have received funding to support IPCC communication activities.

Ethics statement The research was reviewed and approved by the School of Psychology research Ethics Committee, University of East Anglia.

Open Access This article is distributed under the terms of the Creative Commons Attribution 4.0 International License (http://creativecommons.org/licenses/by/4.0/), which permits unrestricted use, distribution, and reproduction in any medium, provided you give appropriate credit to the original author(s) and the source, provide a link to the Creative Commons license, and indicate if changes were made. 


\section{References}

Baldassi S, Megna N, Burr DC (2006) Visual clutter causes high-magnitude errors. PLoS Biol. https://doi. org/10.1371/journal.pbio.0040056

Barkemeyer R, Dessai S, Monge-Sanz B, Renzi BG, Napolitano G (2016) Linguistic analysis of IPCC summaries for policymakers and associated coverage. Nat Clim Chang 6:311-316

Black R (2015) No more summaries for wonks. Nat Clim Chang 5:282-284

Bosetti V, Weber E, Berger L, Budescu DV, Liu N, Tavoni M (2017) COP21 climate negotiators' responses to climate model forecasts. Nat Clim Chang 7:185-191

Brasseur GP, Gallardo L (2016) Climate services: lessons learned and future prospects. Earth's Future 4:79-89

Braun V, Clarke V (2006) Using thematic analysis in psychology. Qual Res Psychol 3:77-101

Budescu DV, Por H-H, Broomell SB, Smithson M (2014) The interpretation of IPCC probabilistic statements around the world. Nat Clim Chang 4:508-512

Clarke V, Braun V, Hayfield N (2015) Thematic analysis. In Smith JA (ed) Qualitative psychology: a practical guide to research methods, third edition Sage, London, pp 222-248

Corner A, Shaw C, Clarke J (2018) Principles for effective communication and public engagement on climate change: a handbook for IPCC authors. Climate Outreach, Oxford https://climateoutreach. org/download/13492. Accessed 25 February 2019

Daron JD, Lorenz S, Wolski P, Blamey RC, Jack C (2015) Interpreting climate data visualisations to inform adaptation decisions. Clim Risk Manag 10:17-26

Evans JSBT, Stanovich KE (2013) Dual-process theories of higher cognition: advancing the debate. Perspect Psychol Sci 8:223-241

Fischer H, Schütte S, Depoux A, Amelung D, Sauerborn R (2018) How well do COP22 attendees understand graphs on climate change health impacts from the fifth IPCC assessment report? Int J Environ Res Public Health. https://doi.org/10.3390/ijerph15050875

Fugard AJB, Potts HWW (2015) Supporting thinking on sample sizes for thematic analyses: a quantitative tool. Int J Soc Res Methodol 18(6):669-684

Harold J, Lorenzoni I, Shipley TF, Coventry KR (2016) Cognitive and psychological science insights to improve climate change data visualization. Nat Clim Chang 6:1080-1089

Hegarty M (2011) The cognitive science of visual-spatial displays: implications for design. Top Cogn Sci 3:446474

Hewitson B, Waagsaether K, Wohland J, Kloppers K, Kara T (2017) Climate information websites: an evolving landscape. WIREs Clim Change. https://doi.org/10.1002/wcc.470

IPCC (2012) IPCC 35th session, 6-9 June 2012, Geneva, Switzerland, Decisions taken with respect to the review of IPCC processes and procedures, Communications strategy https://www.ipcc.ch/site/assets/uploads/2018 /05/IAC_CommunicationStrategy.pdf. Accessed 25 February 2019

IPCC (2013a) Summary for policymakers. In: Stocker TF, Qin D, Plattner G-K, Tignor M, Allen SK, Boschung J, Nauels A, Xia Y, Bex V, Midgley PM (eds) Climate change 2013: the physical science basis. Contribution of working group I to the fifth assessment report of the intergovernmental panel on climate change. Cambridge University Press, Cambridge, pp 3-29

IPCC (2013b) IPCC factsheet: what is the IPCC? https:/www.ipcc.ch/site/assets/uploads/2018/02/FS_what_ ipcc.pdf. Accessed 25 February 2019

IPCC (2016a) IPCC expert meeting on communication meeting report, Lynn J et al. (eds). World Meteorological Organization, Geneva. https://www.ipcc.ch/site/assets/uploads/2018/08/EMR_COM_full_report.pdf. Accessed 25 February 2019

IPCC (2016b) 44 $4^{\text {th }}$ session of the IPCC, 17-20 October 2016, Bangkok, Thailand: Decisions adopted by the Panel https://www.ipcc.ch/site/assets/uploads/2018/04/p44_decisions-1.pdf. Accessed 28 June 2019

IPCC (2016c) 43 ${ }^{\text {rd }}$ session of the IPCC, 11-13 April 2016, Nairobi, Kenya: Decisions adopted by the Panel https:/www.ipcc.ch/site/assets/uploads/2018/05/p43_decisions.pdf . Accessed 25 February 2019

IPCC (2018a) Summary for policymakers, In Masson-Delmotte V, et al. (eds) Global warming of $1.5^{\circ} \mathrm{C}$. An IPCC Special Report on the impacts of global warming of $1.5^{\circ} \mathrm{C}$ above pre-industrial levels and related global greenhouse gas emission pathways, in the context of strengthening the global response to the threat of climate change, sustainable development, and efforts to eradicate poverty. World Meteorological Organization, Geneva. https://report.ipcc.ch/sr15/pdf/sr15_spm_final.pdf. Accessed 25 February 2019

IPCC (2018b) Progress report of the special report on global warming of $1.5^{\circ} \mathrm{C}$. https://www.ipcc. ch/site/assets/uploads/2018/04/130220180459-INF.6-ReportSR-15.pdf. Accessed 25 February 2019

Larkin JH, Simon HA (1987) Why a diagram is (sometimes) worth ten thousand words. Cogn Sci 11:65-100

Lynn J (2018) Communicating the IPCC: challenges and opportunities. In Leal Filho W et al. (eds) Handbook of climate change communication: Vol 3. Climate Change Management, Springer, Cham, pp 131-143. https://doi.org/10.1007/978-3-319-70479-1_8 
Mach KJ, Freeman PT, Mastrandrea MD, Field CB (2016) A multistage crucible of revision and approval shapes IPCC policymaker summaries. Sci Adv. https://doi.org/10.1126/sciadv.1600421

McMahon R, Stauffacher M, Knutti R (2015) The unseen uncertainties in climate change: reviewing comprehension of an IPCC scenario graph. Clim Chang 133:141-154

McMahon R, Stauffacher M, Knutti R (2016) The scientific veneer of IPCC visuals. Clim Chang 138:369-381

Neider MB, Zelinsky GJ (2011) Cutting through the clutter: searching for targets in evolving complex scenes. J Vis. https://doi.org/10.1167/11.14.7

Olivia A, Mack ML, Shrestha M, Peeper A (2004). Identifying the perceptual dimensions of visual complexity of scenes. In Forbus K, Gentner D and Regier T (eds) Proceedings of the annual meeting of the cognitive science society, 26. https://escholarship.org/uc/item/17s4h6w8

Padilla LM, Creem-Regehr SH, Hegarty M, Stefanucci JK (2018) Decision making with visualizations: a cognitive framework across disciplines. Cogn Res Princ Implic. https://doi.org/10.1186/s41235-018-0120-9

Rapley CG, de Meyer K, Carney J, Clarke R, Howarth C, Smith N, Stilgoe J, Youngs S, Brierley C, Haugvaldstad A, Lotto B, Michie S, Shipworth M, Tuckett D (2014) Time for change? Climate science reconsidered, report of the UCL policy commission on communicating climate science. https://www.ucl.ac. uk/drupal/site public-policy/sites/public-policy/files/migrated-files/time-for-change.pdf Accessed 25 February 2019

Rosenholtz R, Li Y, Nakano L (2007) Measuring visual clutter. J Vis. https://doi.org/10.1167/7.2.17

Stocker TF, Plattner G-K (2014) Rethink IPCC reports. Nature 513:163-165

Stocker TF, Plattner G-K (2016) Making use of the IPCC's powerful communication tool. Nat Clim Chang 6: 637-638

Stofer K, Che X (2014) Comparing experts and novices on scaffolded data visualizations using eye-tracking. J Eye Mov Res. https://doi.org/10.16910/jemr.7.5.2

Publisher's note Springer Nature remains neutral with regard to jurisdictional claims in published maps and institutional affiliations. 